\title{
Awareness on Essential Qualities of Teamwork Among College Students - A Survey
}

\author{
Harini. P1, Vishnu Priya. V² and Gayathri. R ${ }^{3}$ \\ ${ }^{1}$ Saveetha Dental College and Hospitals Saveetha Institute of Medical \& Technical \\ sciences ( SIMATS) Saveetha University Chennai - 600077, India \\ ${ }^{2}$ Department of Biochemistry Saveetha Dental College and Hospitals Saveetha Institute \\ of Medical \& Technical Sciences ( SIMATS) Saveetha University Chennai-600077, India \\ ${ }^{3}$ Department of Biochemistry Saveetha Dental College and Hospitals Saveetha Institute of \\ Medical \& Technical Sciences ( SIMATS) Saveetha University Chennai-600077, India
}

\section{ABSTRACT}

Teamwork is a group of members exploring new ideas and moving together towards the same goal. Skills of teamwork can be acquired through experiences. The effective team knows how to use and make the organization in an effective manner. An effective team consists of good leadership, enhanced communication, common goals, motivation and varying useful skills. The aim of the study is to create awareness on the essential qualities of teamwork among college students. Self administrated questionnaire was designed and distributed through an online survey planet link. The Study population included 100 college students belonging to the age group of 18 to 24 years. The participants were explained about the purpose of the study in detail. The questions were carefully studied and the corresponding answers were marked by the participants. The data were collected and statistically analysed. From the data it was reported that most of the participants were interested in engaging in teamwork. Teamwork skills should be taught in colleges which help the individual to work efficiently in their workplaces. Individuals may take time to develop teamwork skills but they should not neglect it. They should continuously learn, practice and pursue teamwork skills. Teamwork enhances the fundamental skills of an individual. It is valuable for college students because it enhances communication skills, leadership skills and it helps in self growth. It fosters friendship, trust and loyalty. Finally teamwork motivates our skills and empowers us.

\section{KEY WORDS: FUNDAMENTAL SKILLS; PRACTICE; MOTIVATION; TEAMWORK, ONLINE SURVEY.}

\section{INTRODUCTION}

Teamwork is defined as a group of members working together in an effective way for a successful intended result. Teamwork is important from school students to military and aviation (Putranto and Woods, 2016) .

\section{ARTICLE INFORMATION}

${ }^{*}$ Corresponding Author: vishnupriya@saveetha.com Received 6th Aug 2020 Accepted after revision 24th Sep 2020 Print ISSN: 0974-6455 Online ISSN: 2321-4007 CODEN: BBRCBA

Thomson Reuters ISI Web of Science Clarivate Analytics USA and Crossref Indexed Journal

\section{Clarivate
Analytics}

NAAS Journal Score 2020 (4.31) SJIF: 2020 (7.728)

A Society of Science and Nature Publication,

Bhopal India 2020. All rights reserved.

Online Contents Available at: http//www.bbrc.in/

Doi: http://dx.doi.org/10.21786/bbrc/13.8/145
Teamwork is a cooperative process that allows ordinary people to achieve extraordinary results. It can also be defined that in the team a group of members walk towards a common goal developing cooperative skills and mutual relationships (Beigi and Shirmohammadi, 2012) . There are some para metres which contribute to the team work. Individuals engaged in teamwork have good interaction with teammates, expect good quality, keep the team on track, good social skills, and have relevant knowledge and abilities (Pineda and Lerner, 2006). Leadership plays a great role for good teamwork. If leadership and teamwork go hands in hands they may bring forth the positive outcome. As teamwork helps in real life challenges there is a necessity to concentrate on the developing teamwork skills (Hunziker et al., 2011). 
In multi-disciplinary fields like a medicine, teamwork is much more important. The major problem to be observed is the attitude and character, which vary for different individuals and the team work will be running along with that. The positive attitude depends on positive outcomes (Firth-Cozens, 2001). There are two types of knowledge in teamwork. They are task-work knowledge and teamwork knowledge. So the educators and managers should be good enough to form the team with these types of knowledge (Guchait, Lei and Tews, 2016). The ability of an individual to work in a team in their respective workplaces should be taught in universities. Strategies like assigning a reasonable workload, using peer evaluations and allowing students on group projects which improves students teamwork experiences (Pfaff and Huddleston, 2003). It may take time for an individual to transit from self work to teamwork, it may take much time but it should not be neglected (Moe, Dingsøyr and Dybå, 2010). Active listening, increased cooperation and more discussions are seen only in teamwork (Hazzan and Dubinsky, 2010) .

Other studies were done in an unselected population whereas present study focuses on the South Indian population especially college students. Most of the studies did not focus on the importance of creating awareness about teamwork and did not concentrate on the effectiveness of essential teamwork in the future. Previous studies on Cancer biology, nano materials, herbal products (Ponnulakshmi et al., 2019) (Chen et al., 2019) (Surapaneni and Jainu, 2014) (Wu et al., 2019) (Ke et al., 2019; Ma et al., 2019) have motivated me to pursue this current research which is useful to our community. The aim of the study is to create awareness on essential teamwork and to highlight the factors like trust, leadership and performance which is associated with teamwork.

\section{MATERIAL AND METHODS}

Self administered questionnaires were designed based on the attitude and knowledge of the participants. The questions were circulated to the age group of 18 to 24 years and circulated among 100 undergraduate college students. It was circulated using the Survey Planet link and a list of output variables were included. A statistical test was done using a software SPSS. Statistical test used descriptive analysis and frequency percentage. Descriptive variables like age, year of study, gender and explanatory variables like personality trait, knowledge, attitude and practice were also included. Each output variable was collected as ordinal data and the collected data were represented as pie charts. Exclusion criteria of the study were participants not willing to participate and medically compromised participants. Some of the inclusion criteria was participants above 18 years of age, college students and participants who can understand and fill the questionnaire.

\section{RESULTS AND DISCUSSION}

The present Study was conducted among college students including both male and female. It was good to know that most of the college students are aware of teamwork. $89.11 \%$ of the population responded that a positive attitude is important for good team work ( Figure 1.1). $79.21 \%$ of the population had a view that common goals are seen in each and every individual who is the part of team work ( Figure 1.2). 76.24 \% of the population reported that interdependence is a part of teamwork (Figure 1.3).

Figure 1.1: Pie chart showing percentage distribution of positive attitude helps for developing good teamwork. $89.11 \%$ of the participants reported yes (blue) and $10.89 \%$ of them reported no (red).

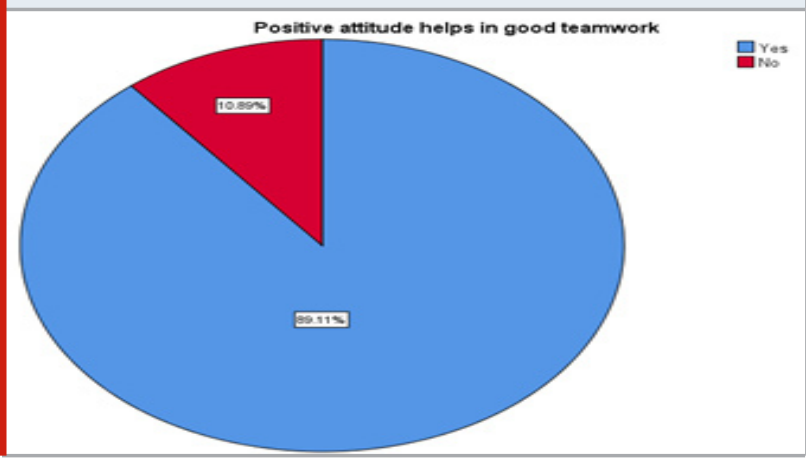

Figure 1.2 Pie chart showing the percentage distribution of common goals improves teamwork. $79.21 \%$ reported yes (blue) and 20.79\% of them reported no (red).

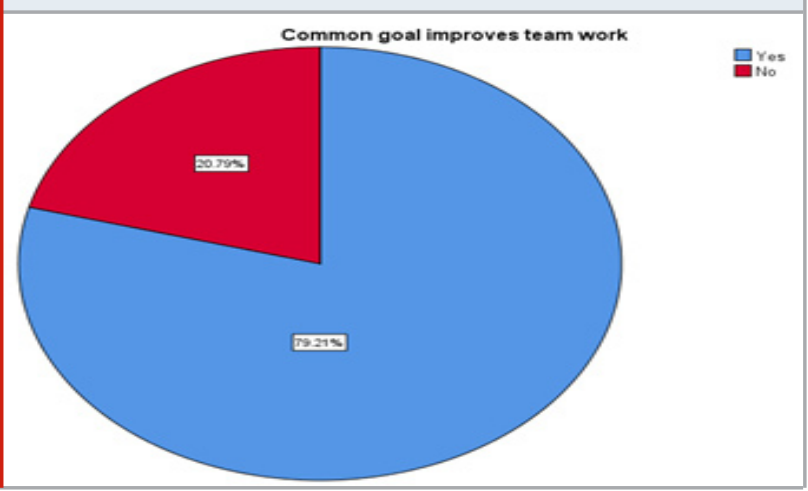

Figure 1.3 Pie chart showing percentage distribution of good interdependence is a part of teamwork. 76.24\% of the population reported yes (blue) and 23.76\% of them reported no (red).

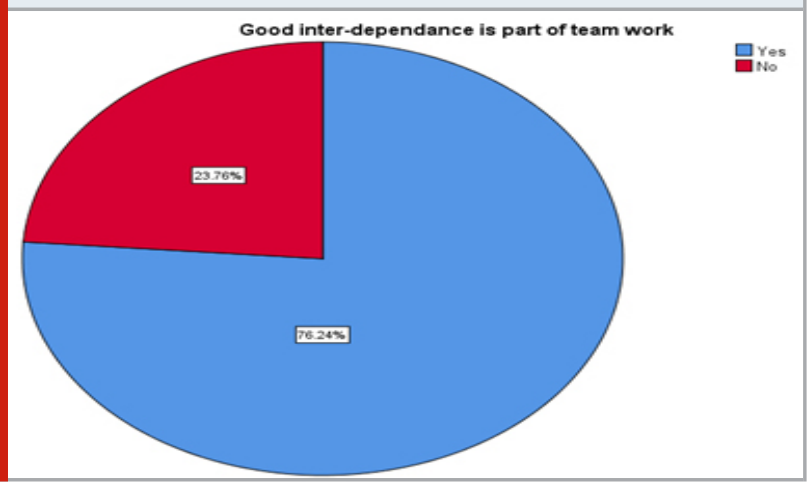


$83.17 \%$ of the respondents responded that teamwork was more successful rather than individual work (figure 1.4 ). $75.25 \%$ of them had an idea that teamwork was more important in colleges than other sectors (figure 1.5). 79.21 $\%$ of the population reported that motivation is important in teamwork for achieving their goals (figure 1.6). 65.35 $\%$ of the population reported that friendship and trust is seen more in teamwork which is the best quality for good and effective teamwork (figure 1.7). $72.28 \%$ of the population reported that probability of conflict is more in team work when compared to individual work (figure 1.8). $81.19 \%$ of the participants reported that teamwork gives satisfaction than individual work ( figure 9 ).

Figure 1.4: Pie chart showing percentage distribution of teamwork is more successful than individual work. 83.17\% of the population reported yes (blue) and $16.83 \%$ of them reported no (red).

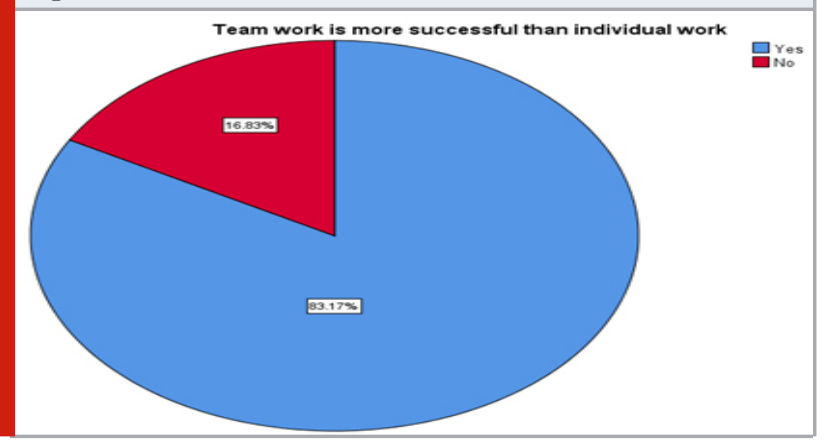

Figure 1.5: Pie chart showing percentage distribution of teamwork is important in colleges. $75.25 \%$ of the population reported yes (blue) and $24.75 \%$ of them reported no (red).

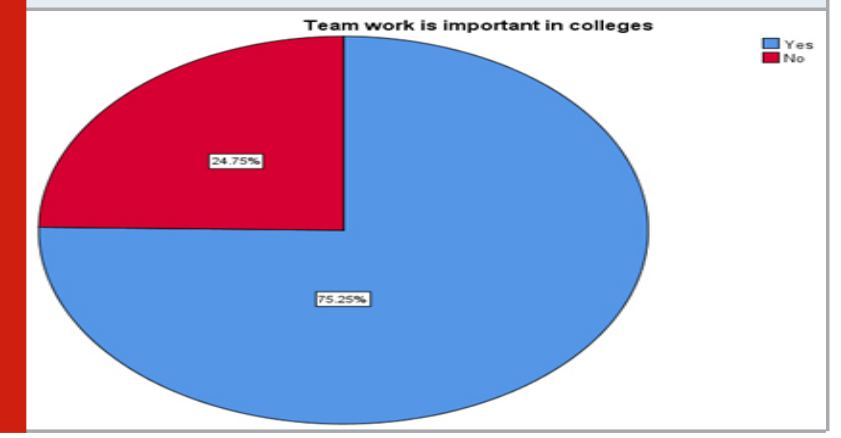

Figure 1.6: Pie chart showing percentage distribution of motivation is important in teamwork. 79.21\% of the population reported yes (blue) and 20.79\% of them reported no (red).

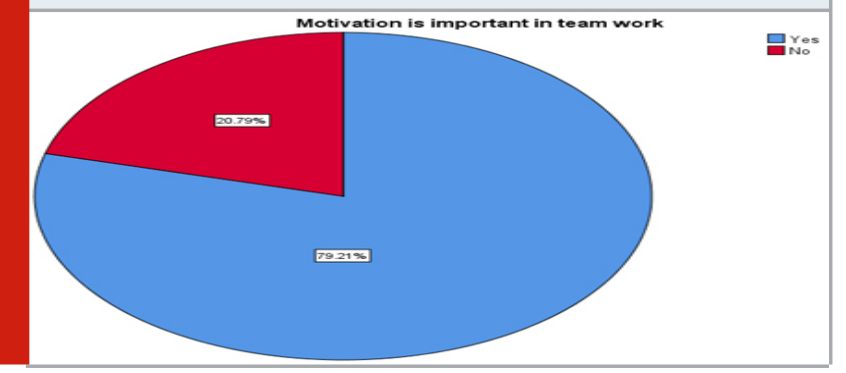

Figure 1.7: Pie chart showing percentage distribution of teamwork enhances friendship and trust. 65.35\% of the population reported yes (blue) and 34.65\% of them reported no (red).

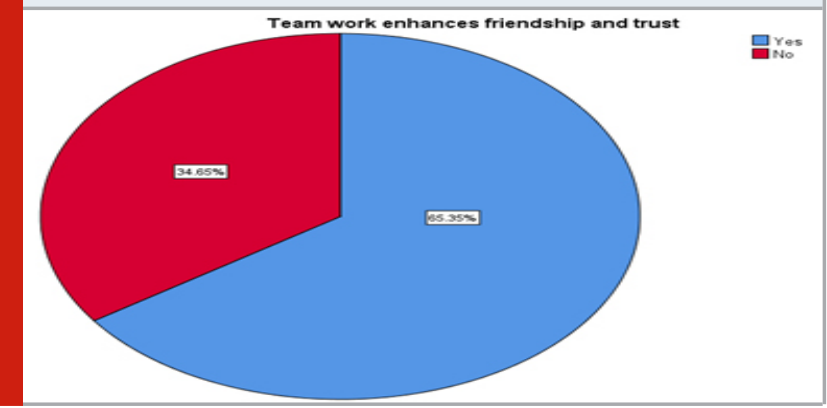

Figure 1.8: Pie chart showing percentage distribution of probability of conflict is more in teamwork. $72.28 \%$ of the population reported yes (blue) and 27.72\% of the population reported no (red).

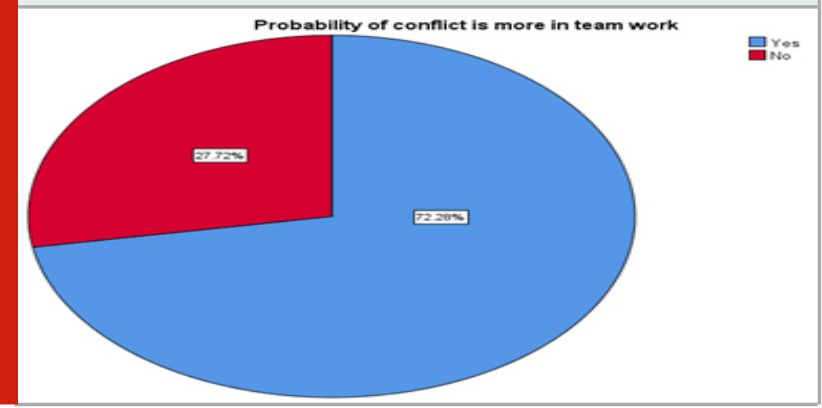

Figure 1.9: Pie chart showing percentage distribution of teamwork gives satisfaction than individual work. $81.19 \%$ of the population reported yes (blue) and $18.81 \%$ of the population reported no (red).

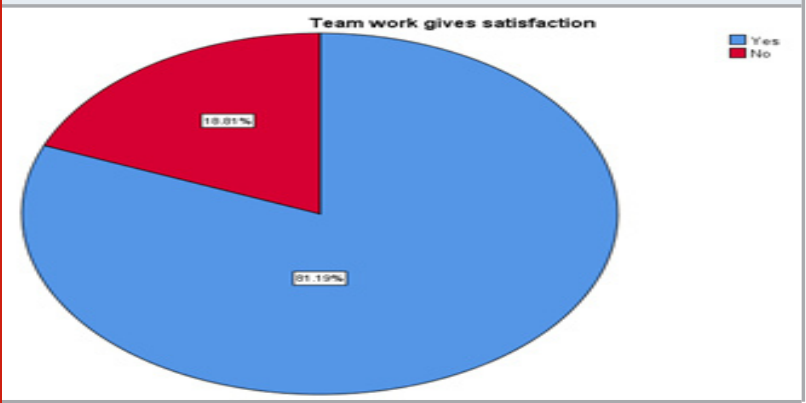

When the participants were enquired about the essential qualities of teamwork $67.33 \%$ of the population reported that teamwork offers different perspectives (figure 1.10). It was good to know that $72.28 \%$ of the population assumed that teamwork improves unity (figure1.11). $73.27 \%$ of the population reported that teamwork improves self confidence and self awareness (figure 1.12). 71.29\% of the participants reported that teamwork gives opportunity for learning (figure 1.13). $74.26 \%$ of the population said that flexibility is more important for good teamwork (figure 1.14). 71.29 \% of the participants had a view that teamwork produces a variety of skills which can be used later in workplaces 
and teamwork skills help to face the real life time challenges (figure 1.15).

Figure 1.10: Pie chart showing percentage distribution of teamwork offers different perspectives for an individual. $67.33 \%$ of the population reported yes (blue) and $32.67 \%$ of the population reported no (red).

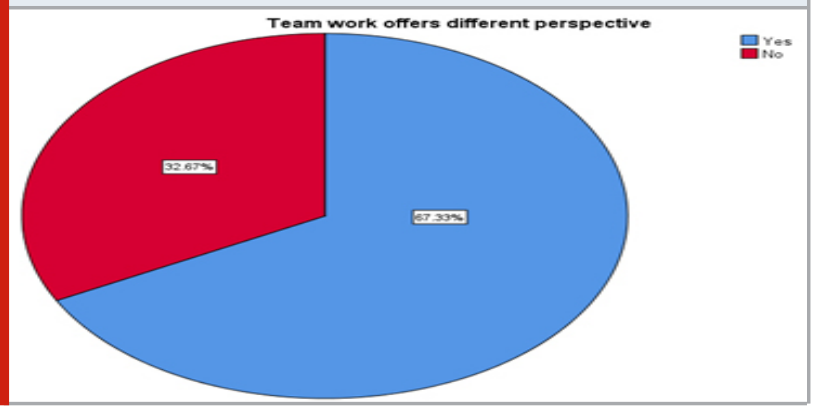

Figure 1.11: Pie chart showing percentage distribution of teamwork motivates unity rather than individual work. $\mathbf{7 2 . 2 8} \%$ of the population reported yes (blue) and $27.72 \%$ of the population reported no (red).

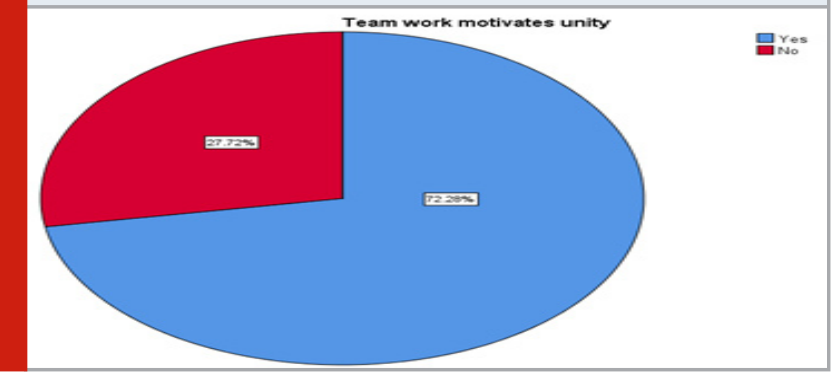

Figure 1.12: Pie chart showing percentage distribution of teamwork improves self confidence. $73.27 \%$ of the population reported yes (blue) and 26.73\% of the population reported no (red).

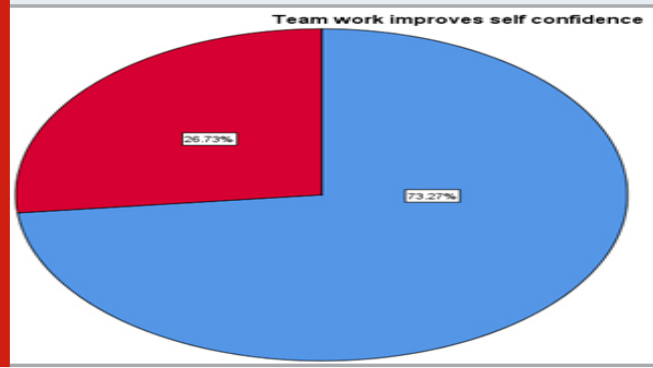

Figure 1.13: Pie chart showing percentage distribution of teamwork provides learning opportunities. $71.29 \%$ of the population reported yes (blue) and $28.71 \%$ of the population reported no (red).

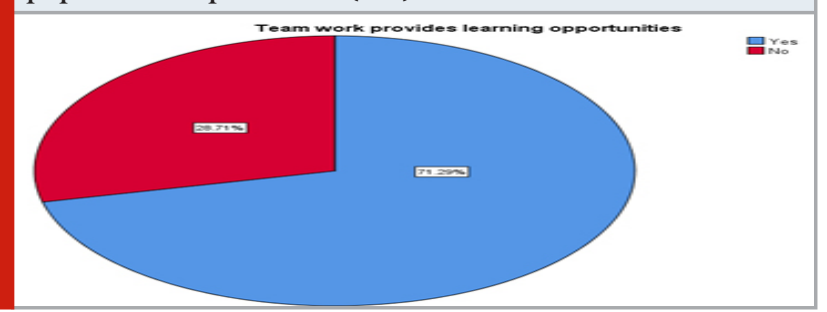

Figure 1.14: Pie chart showing percentage distribution of flexibility is important in teamwork. $74.26 \%$ of the population reported yes (blue) and $25.74 \%$ of the population reported no (red).

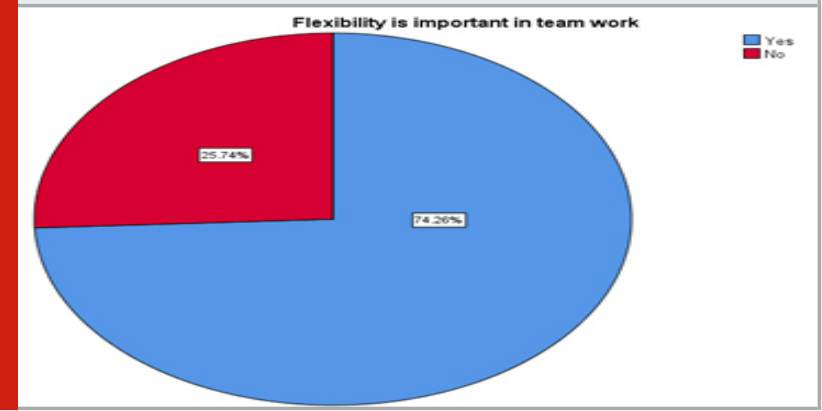

Figure 1.15: Pie chart showing percentage distribution of teamwork produces variety of skills. $71.29 \%$ of the population reported yes (blue) and $28.71 \%$ of the population reported no (red).

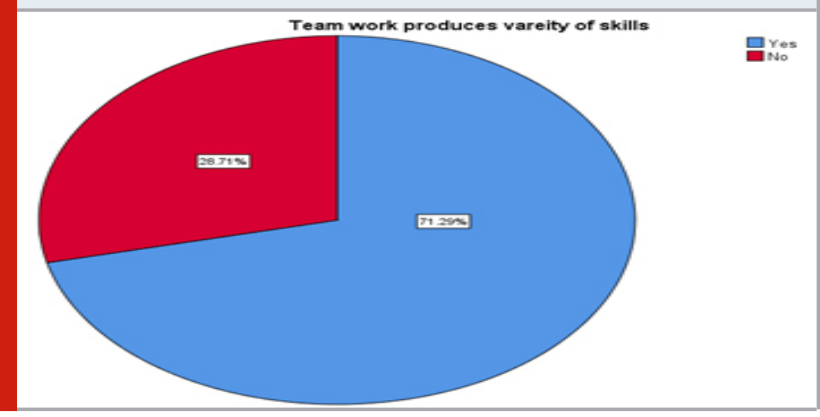

$62.38 \%$ of the population responded that adaptability is an important parameter for teamwork to achieve their common goals (figure 1.16). 69.31\% of the population responded that teamwork helps the individual to focus on their personal growth ( figure 1.17). 72.28\% of the population responded that comfortability is good enough in a potential teamwork (figure 1.18 ). $81.19 \%$ of the respondents responded that equal participation is not seen in teamwork which is a major drawback seen in teamwork ( figure 1.19). When the participants were enquired about the most required skills for perpetual teamwork, $28.71 \%$ of the population responded that trust is the important quality that is required for achieving a successful team and to keep the team on track (Figure 1.20).

Figure 1.16: Pie chart showing percentage distribution of adaptability is important in teamwork. $62.38 \%$ of the population reported yes (blue) and $37.62 \%$ of the population reported no (red).

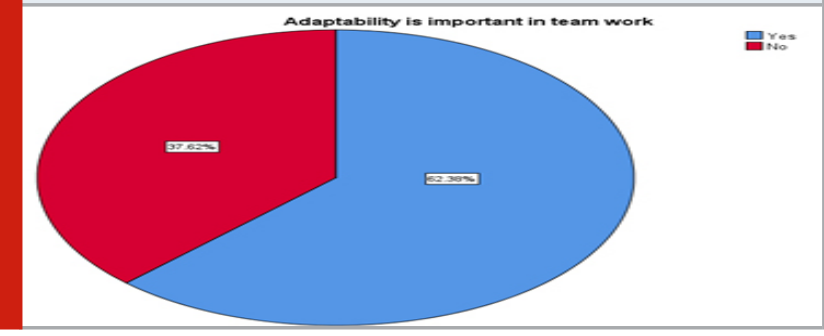


Figure 1.17: Pie chart showing percentage distribution of teamwork helps in personal growth. $69.31 \%$ of the population reported yes (blue) and $30.69 \%$ of the population reported no (red).

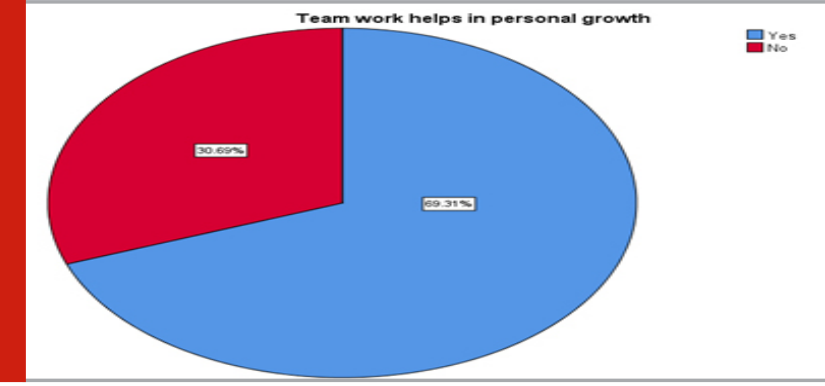

Figure 1.18: Pie chart showing percentage distribution of teamwork produces comfortability. $72.28 \%$ of the population reported yes (blue) and $27.72 \%$ of the population reported no (red).

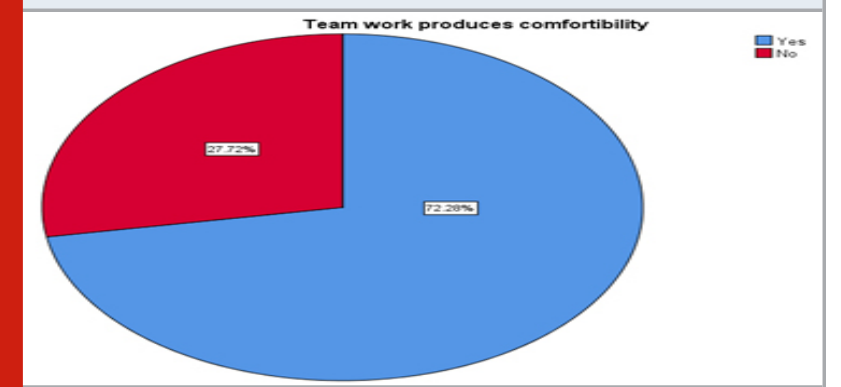

Figure 1.19: Pie chart showing percentage distribution of equal participation is seen in teamwork. $81.19 \%$ of the population reported yes (blue) and $18.81 \%$ of the population reported no (red).

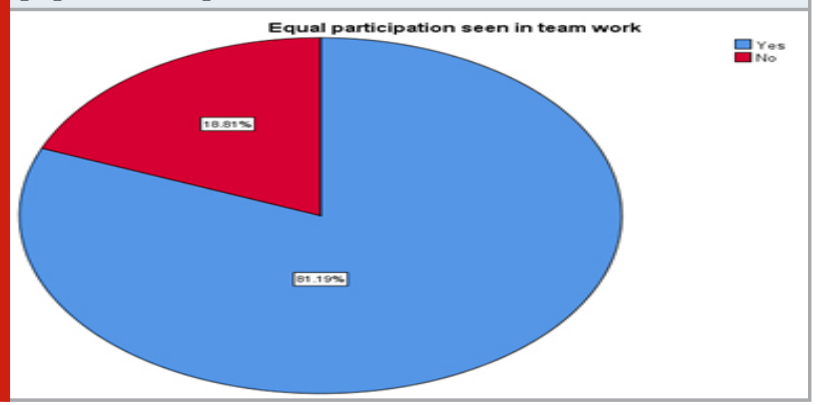

Gilbert in his study reported that positive attitude and virtuous practises were the necessary criteria for effective team work . Present study also reported that a positive attitude is an encouraging factor for better teamwork (Gilbert and Ronald Gilbert, 1985) . Randall S. Hansen in his study stated that knowledge is not always required in teamwork but it is one of the most important parameters for better teamwork compared to the present study; it also stated that knowledge is an important parameter to sail the team (Hansen, 2006). Martine Hass in her study reported that there are more obstacles in teamwork. To solve that lots of effort should be done. Leader of a team should make an ordinary person an extraordinary person and help them to solve the problem. The present study also stated that leadership is an important quality for better teamwork (Haas and Mortensen, 2016) . Some of the previous studies proposed that humans are more likely to do Individual work rather than doing teamwork.

Figure 1.20: Pie chart showing percentage distribution of skills required for effective teamwork. $28.71 \%$ of the population reported trust as an important skill (red), $27.72 \%$ of the population reported attitude as an important skill (blue), $23.76 \%$ of the them reported management as an important skill (green) and $19.80 \%$ of the population reported leadership as an essential quality (orange).

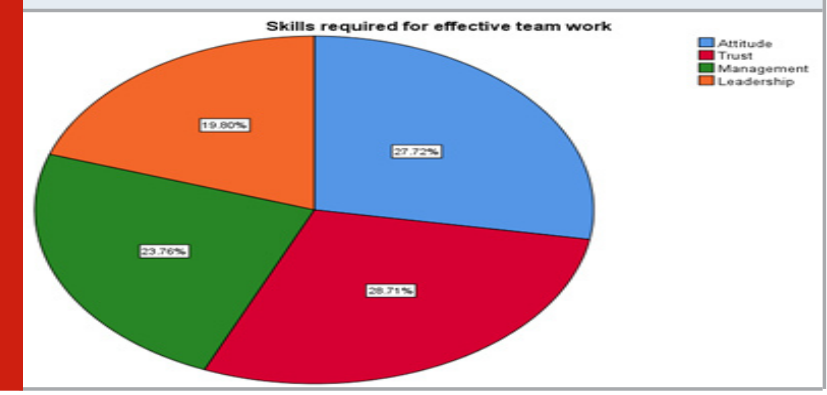

They think that teamwork consists of lots of work and it requires a lot of effort. When comparing the previous study and present study more than half the population responded that they have more desire to work as a team (Riebe, Girardi and Whitsed, 2016). Some of the previous study also reported that being a leader for a team is a personal and individual ability of a person. If the person wanted to be a leader and govern the whole team he must be the person with more courage. When comparing both the studies the previous study told that it is important and more enough to have courage alons for leaders to work but the present study employs that courage is an essential parameter for each and everyone in the team (Barak, Maymon and Harel, 1999). There were some limitations that should be noted in the study. The limitations of the study were less sample size, homogeneous population, response bias and survey fatigue. And it is noteworthy to mention the future scope of the present study. Teamwork is a life skill. Encouraging teamwork in a college helps the students to express their ideas and opinions confidently in their work places.

\section{CONCLUSION}

If you want to walk fast, walk alone ; if you want to walk far walk with a team'. Working with a team helps to find a solution even for the biggest problems. It empowers your communication skills, leadership quality, it enhances friendship and trust. It is important for every individual to develop their teamwork skills . In teamwork the work of an individual is valued and successful results can be obtained. Teamwork is important among college students because it teaches communication skills, social skills and it motivates the students to listen to their leaders and coaches. 


\section{ACKNOWLEDGEMENTS}

We thank Saveetha Dental College for providing us the support to conduct the study.

\section{Conflict of Interest: Nil}

\section{REFERENCES}

Barak, M., Maymon, T. and Harel, G. (1999) 'Teamwork in Modern Organizations: Implications for Technology Education', International Journal of Technology and Design Education, pp. 85-101. doi: 10.1023/ a:1008849803984.

Beigi, M. and Shirmohammadi, M. (2012) 'Attitudes toward teamwork: are Iranian university students ready for the workplace?', Team Performance Management: An International Journal, pp. 295-311. doi: $10.1108 / 13527591211251087$.

Chen, F. et al. (2019) '6-shogaol, a active constiuents of ginger prevents UVB radiation mediated inflammation and oxidative stress through modulating $\mathrm{NrF} 2$ signaling in human epidermal keratinocytes (HaCaT cells)', Journal of photochemistry and photobiology. B, Biology, 197, p. 111518.

Firth-Cozens, J. (2001) 'Multidisciplinary teamwork: the good, bad, and everything in between', Quality in Health Care, pp. 65-66. doi: 10.1136/qhc.10.2.65.

Gilbert, C. R. and Ronald Gilbert, C. (1985) 'Building Highly Productive Work Teams through Positive Leadership', Public Personnel Management, pp. 449454. doi: 10.1177/009102608501400415.

Guchait, P., Lei, P. and Tews, M. J. (2016) 'Making Teamwork Work: Team Knowledge for Team Effectiveness', The Journal of psychology, 150(3), pp. 300-317.

Haas, M. and Mortensen, M. (2016) 'The Secrets of Great Teamwork', Harvard business review, 94(6), pp. 70-6, 117.

Hansen, R. S. (2006) 'Benefits and Problems With Student Teams: Suggestions for Improving Team Projects', Journal of Education for Business, pp. 11-19. doi: 10.3200/joeb.82.1.11-19.

Hazzan, O. and Dubinsky, Y. (2010) 'Students' cooperation in teamwork', Proceedings of the ACM international conference companion on Object oriented programming systems languages and applications companion SPLASH '10. doi: 10.1145/1869542.1869566.

Hunziker, S. et al. (2011) 'Teamwork and leadership in cardiopulmonary resuscitation', Journal of the American College of Cardiology, 57(24), pp. 2381-2388.

Ke, Y. et al. (2019) 'Photosynthesized gold nanoparticles from Catharanthus roseus induces caspase-mediated apoptosis in cervical cancer cells (HeLa)', Artificial cells, nanomedicine, and biotechnology , 47(1), pp. 1938-1946.

Ma, Y. et al. (2019) 'Sesame Inhibits Cell Proliferation and Induces Apoptosis through Inhibition of STAT-3 Translocation in Thyroid Cancer Cell Lines (FTC-133)', Biotechnology and bioprocess engineering: BBE, 24(4), pp. 646-652.

Moe, N. B., Dingsøyr, T. and Dybå, T. (2010) 'A teamwork model for understanding an agile team: A case study of a Scrum project', Information and Software Technology, pp. 480-491. doi: 10.1016/j.infsof.2009.11.004.

Pfaff, E. and Huddleston, P. (2003) 'Does It Matter if I Hate Teamwork? What Impacts Student Attitudes toward Teamwork', Journal of Marketing Education, pp. 37-45. doi: 10.1177/0273475302250571.

Pineda, R. C. and Lerner, L. D. (2006) 'Goal attainment, satisfaction and learning from teamwork', Team Performance Management: An International Journal, pp. 182-191. doi: 10.1108/13527590610687938.

Ponnulakshmi, R. et al. (2019) 'In silico and in vivo analysis to identify the antidiabetic activity of beta sitosterol in adipose tissue of high fat diet and sucrose induced type-2 diabetic experimental rats', Toxicology mechanisms and methods, 29(4), pp. 276-290.

Putranto, N. A. R. and Woods, P. (2016) 'Comparison Indonesian and Australian Students' Cultural Intelligence and Attitude towards Teamwork: Case study of Institut Teknologi Bandung and Griffith University', Sains Humanika. doi: 10.11113/sh.v8n1-2.833.

Riebe, L., Girardi, A. and Whitsed, C. (2016) 'A Systematic Literature Review of Teamwork Pedagogy in Higher Education', Small Group Research, pp. 619-664. doi: $10.1177 / 1046496416665221$.

Surapaneni, K. and Jainu, M. (2014) 'Pioglitazone, quercetin and hydroxy citric acid effect on hepatic biomarkers in Non Alcoholic Steatohepatitis', Pharmacognosy Research, p. 153. doi: 10.4103/09748490.129037.

$\mathrm{Wu}$, F. et al. (2019) 'Biologically synthesized green gold nanoparticles from Siberian ginseng induce growth-inhibitory effect on melanoma cells (B16)', Artificial Cells, Nanomedicine, and Biotechnology, pp. 3297-3305. doi: 10.1080/21691401.2019.1647224. 